\title{
Team-Based Learning Applied to a Medicinal Chemistry Course
}

\author{
D. Eric Walters
}

Department of Pharmaceutical Sciences, Rosalind Franklin University of Medicine and Science, North Chicago, III., USA

Team-based learning (TBL) is a teaching technique that was developed in the late 1970s by Larry Michaelsen in the Business School of the University of Oklahoma, Norman, Okla., USA $[1,2]$. Recently, TBL has been applied to courses in the pharmacy curricula [3, 4]. Here I describe my experience using TBL methodology in a medicinal chemistry course I recently taught.

Medicinal chemistry encompasses a number of important concepts related to the chemical structure of drug molecules, including $\mathrm{pK}_{\mathrm{a}}$ and $\mathrm{pH}$ behavior, solubility, stability, absorption, distribution, metabolism, excretion, and structure-activity relationships. Traditionally, it has been taught as a lecture. In a lecture format, it is easy for students to regard the subject matter as a list of facts to be memorized. However, according to Bloom's taxonomy of learning [5], remembering facts is the most fundamental level of learning; understanding, applying, analyzing, and evaluating are successively higher levels of learning. Using the lecture methodology, it is challenging to go beyond remembering and understanding, the first levels of Bloom's taxonomy of learning. In TBL, the goal is to encourage students to remember and understand before coming to class and then during the class session to analyze and apply the concepts presented using teams.

The first step in TBL is to provide students with highly focused reading assignments. For this medicinal chemistry course, the readings came primarily from Foye's Principles of Medicinal Chemistry, occasionally supplemented with primary literature. In a few instances, a 5- to 10 -min 'minilecture' was recorded and posted, the only lectures in the course. Each reading assignment explic- itly stated what factual material needed to be learned prior to the class session.

This course met for a 2-hour session, once a week. At the beginning of each session, the students took a 10-question quiz that tested the recall and understanding of the factual information in the reading assignment. The weekly quiz motivated each student to come prepared.

At the end of the quiz, the students handed in their individual quizzes and assembled in teams of 5-6 students formed on the first day of class who remained together throughout the course. Each team then took the same quiz, forcing the students to spend time discussing any facts or concepts that may not have been completely clear to all members of the team. Team answers were recorded and posted on an Instant Feedback-Assessment Technique (IF-AT), a scratch-off card for which the correct answer has a star underneath. The students received immediate feedback - the star was an instant reward. If the first answer chosen was incorrect, the students had then to discuss why that answer was wrong, and what the correct answer was. Time and effort were directed to the facts and concepts for which the students needed further clarification based on their incorrect responses. Points were awarded on a 5-3-2-1-0 basis, depending on how many attempts were needed to find the correct answer. The team score also counted toward each individual's grade.

When the individual and team quizzes were completed, there was a 5 -min break. During this time, the teams could appeal any question they felt might have had an alternate answer. The textbook and credible online resources could be used. This method forced the students

\section{KARGER}

Fax +4161306 1234

E-Mail karger@karger.ch

www.karger.com (c) 2012 S. Karger AG, Basel

$1011-7571 / 13 / 0221-0002 \$ 38.00 / 0$

Accessible online at:

www.karger.com/mpp
Prof. D. Eric Walters

Department of Pharmaceutical Sciences, College of Pharmacy

Rosalind Franklin University of Medicine and Science

North Chicago, IL 60064 (USA)

E-Mail Eric.Walters@ RosalindFranklin.edu 
Table 1. Grading scheme

\begin{tabular}{lr}
\hline Individual components (65\%) & \\
Individual quizzes & $20 \%$ \\
Midterm exam & $20 \%$ \\
Final exam & $25 \%$ \\
Team components (35\%) & $15 \%$ \\
Team quizzes & $15 \%$ \\
Team problem solving & $5 \%$ \\
Peer evaluation & \\
\hline
\end{tabular}

to reexamine concepts with which they were still struggling. During this time, the team scorecards were reviewed to see which questions caused the most difficulty. When necessary, a few minutes immediately after the break were dedicated to clarifying a concept.

The quizzes and appeals usually took $30-35 \mathrm{~min}$, leaving almost an hour and a half to apply the factual and conceptual information using the team-based problemsolving method. During the problem-solving part of class, the students could use their textbooks and online information resources, allowing the instructor to pose more challenging problems in which the students could go beyond just memorizing facts and engage in higherorder thinking skills according to Bloom's taxonomy.

The problems were set up with multiple-choice answers, each team working together to solve the same problem. When the teams had completed their research, each held up an answer simultaneously. As the instructor, I could immediately see whether all the teams came to the same conclusion. I could then walk around the room with a wireless microphone and ask the teams to explain why they chose a particular answer, how they ruled out another answer, and what kinds of information they needed to solve the problem. When teams arrived at different answers, I could facilitate a discussion of the underlying concepts. This problem-solving session involved the students in higher levels of learning (applying, analyzing and evaluating).

This portion of the course was graded solely on participation. Questions could be written that didn't necessarily have a single best answer, which led to good discussion in this course of the pros and cons of different drug choices. This portion of the course benefitted enormously from the participation of several Pharmacy Practice faculty members (see Acknowledgments). They helped me to craft relevant and challenging problems, and they were willing participants in the in-class discussions.

The grading scheme emphasized both individual and team performance (table 1). It also included a peer evalu- ation component, which included both written comments and a numerical score. The students wrote one positive comment and one constructive suggestion for each team member and distributed 100 points among the other team members, with no 2 students getting identical scores. This forced the students to make some judgments about the performance of teammates.

Student evaluations showed that the TBL approach was generally well received. About $95 \%$ of the respondents agreed that the reading assignments were focused and helpful, and about $81 \%$ of them agreed or strongly agreed that they enjoyed the TBL format.

I found that TBL took at least as much effort as I would have spent preparing new lectures. In particular, preparing well-focused reading assignments and challenging problems took several hours per week. Nevertheless, I thoroughly enjoyed the result. There were no boring lectures. Attendance was outstanding. The teams became cohesive and competitive, and peer pressure ensured that every student came to class with some level of preparation. Most importantly, the students gained a solid understanding of a sometimes difficult topic.

\section{Acknowledgments}

I am deeply indebted to my Pharmacy Practice colleagues for their enthusiastic participation in problem-writing and in-class discussion: Dan Albertson, PhD, RPh; Scott Hanes, PharmD; Jamie Holmes, PharmD; Sekhar Mamidi, PharmD, and Lisa Michener, Pharm D. I am truly grateful to the College of Pharmacy's Class of 2015, who participated in this experiment with me and who provided their frank and constructive feedback throughout. I thank Lane Brunner, $\mathrm{PhD}, \mathrm{RPh}$, and Tibebe Woldemariam, $\mathrm{PhD}$, for helpful discussions about TBL and grading schemes.
References
1 Michaelsen LK, Knight AB, Fink LD: Team- Based Learning. Sterling, Stylus Publishing, 2002.
2 Michaelsen LK, Parmelee DX, McMahon KK, Levine RE: Team-Based Learning for Health Professions Education. Sterling, Sty- lus Publishing, 2007.
-3 Grady SE: Team-based learning in pharma- cotherapeutics. Am J Pharm Educ 2011;75: 136.
4 Persky AM: The impact of team-based learn- ing on a foundational pharmacokinetics course. Am J Pharm Educ 2012;76:31.
5 Bloom BS, Engelhart MD, Furst EJ, Hill WH, Krathwohl DR: Taxonomy of Educational Objectives: The Classification of Education- al Goals. Handbook I: Cognitive Domain. New York, Longmans \& Green, 1956. 